\title{
A Case of Inflammatory Pseudotumor Cerebri and Nasal Septum
}

\author{
Ah Ra Jung, Young Min Hah, Jeong Wook Kang, and Kun Hee Lee \\ Department of Otorhinolaryngology-Head and Neck Surgery, School of Medicine, Kyung Hee University, Seoul, Korea
}

\section{대뇌와 비중격에 발생한 염증성 가성종양 1 예}

정아라 · 하영민 · 강정욱 · 이건희

경희대학교 의학전문대학원 이비인후과학교실

\author{
Received March 15, 2016 \\ Revised June 17,2016 \\ Accepted June 27, 2016 \\ Address for correspondence \\ Kun Hee Lee, MD, PhD \\ Department of Otorhinolaryngology- \\ Head and Neck Surgery, \\ School of Medicine, \\ Kyung Hee University, \\ 892 Dongnam-ro, Gangdong-gu, \\ Seoul 05278, Korea \\ Tel $+82-2-440-6181$ \\ Fax $+82-2-440-7336$ \\ E-mail nose4u@gmail.com
}

Inflammatory pseudotumors, which clinically mimic neoplasms, are space-occupying collections of inflammatory cells, histiocytes, and fibroblasts. They are most often found in the orbits and lungs, but rarely in the head and neck region, and hardly ever in the nasal septum. Here we report on a 71-year-old woman with pseudotumor cerebri and an inflammatory pseudotumor of the nasal septum. This case demonstrates that inflammatory pseudotumor can cooccur in the brain and nasal septum.

Korean J Otorhinolaryngol-Head Neck Surg 2017;60(2):83-6

Key Words Inflammatory pseudotumor · Nasal septum · Pseudotumor cerebri.

\section{Introduction}

An inflammatory pseudotumor (IPT) is an idiopathic, benign, inflammatory lesion that is rarely identified in the brain or nasal septum. This lesion is known by a variety of names, including IPT, plasma cell granuloma, pseudosarcomatous (myofibroblastic) tumor lesion, and inflammatory myofibroblastic tumor. Although most commonly found in the lung or orbit, IPTs have been identified at most anatomic locations in the body. Their etiology remains unknown. Sometimes the clinical presentation and imaging studies have an aggressive appearance, which causes much difficulty in diagnosis and treatment. It is important to be aware of this entity because its clinical and radiographic presentation mimics that of an aggressive neoplasm. Here we report a rare case of pseudotumor cerebri and IPT of the nasal septum that was treated successfully by surgical resection and steroids.

\section{Case}

A 71-year-old woman was referred because of diplopia and left ptosis. She had undergone a Caldwell-Luc operation for left maxillary sinusitis five years earlier and had been well until one month before admission, when she developed intermittent stabbing headache. Her symptoms had worsened rapidly, causing diplopia, impaired ocular movement, ptosis, and decreased visual acuity. On magnetic resonance imaging, an enhancing lesion was observed in the left cavernous sinus and in the dura (Fig. 1), where it involved the optic canal (white arrow). A lumbar puncture was performed, but there were no significant findings on analysis of the cerebrospinal fluid. No bacteria, acid-fast bacilli, or fungal organisms were seen on smears or cultures, and cytologic examination revealed no malignant cells. IPT was suspected, so she was initially treated with intravenous corticosteroid ther- 

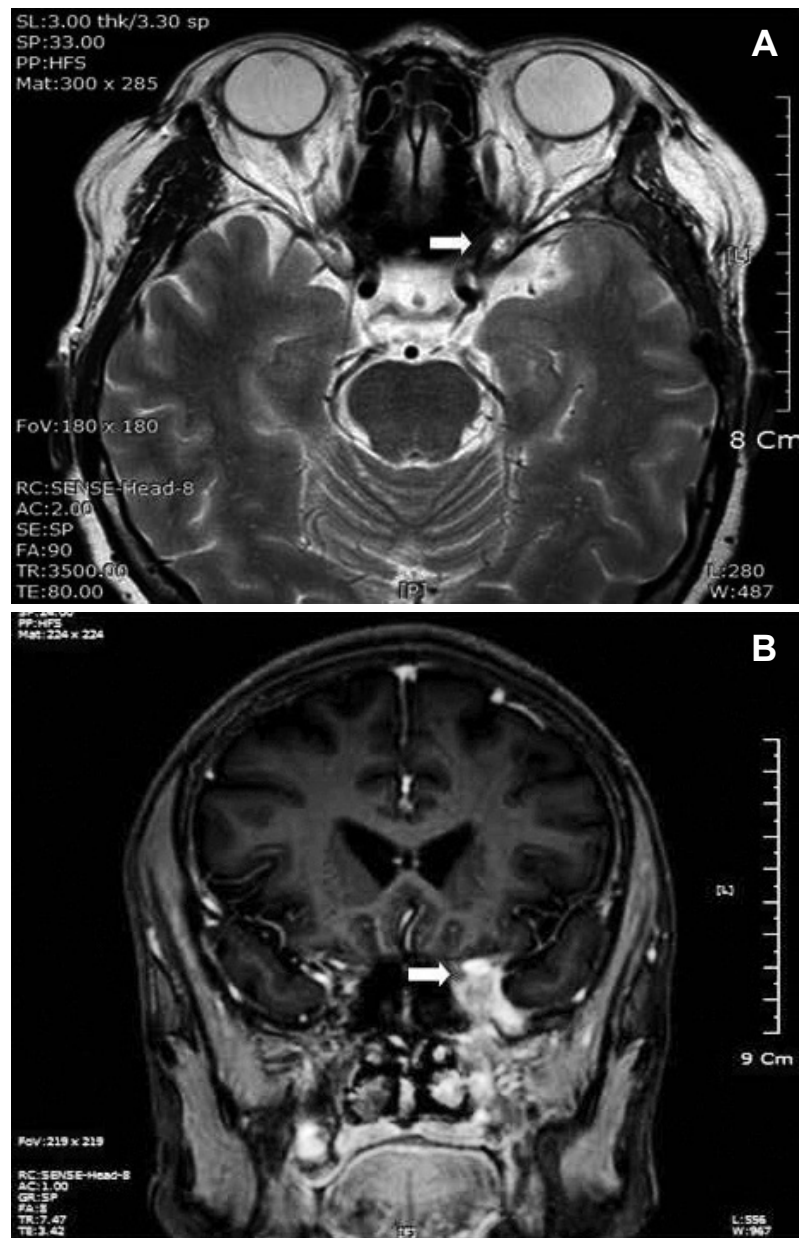

Fig. 1. Pretreatment magnetic resonance image demonstrating a mass (white arrow) in the left cavernous sinus and dura. Axial $\mathrm{T} 2+\mathrm{C}(\mathrm{A})$. Coronal $\mathrm{T} 2+\mathrm{C}$. The axial and coronal T2-weighted images demonstrate abnormal soft tissue (white arrow) at the left cavernous sinus with invasion of the optic canal (B)

apy (methylprednisolone $375 \mathrm{mg} /$ day) after a further 3 days; The patient's ocular symptoms improved three days after starting intravenous corticosteroid therapy. An open biopsy of the left temporal lobe meninges performed via an extended pterional approach confirmed an inflammatory myofibroblastic tumor (IPT cerebri).

At follow-up nine months later, the patient was found to have a nasal obstruction, nasal stuffiness, and hyposmia. On computed tomography, a soft tissue density mass was found at the nasal septum, and involved the ethmoid roof, perpendicular plate, and crista galli (Fig. 2). Transnasal endoscopic extirpation of the tumor was performed under general anesthesia. The tumor was a like granulation tissue with smooth surface originated form the posterior end of the nasal septum. The tumor was removed by en bloc resection at the posterior edge of the nasal septum, with minimal blood loss and
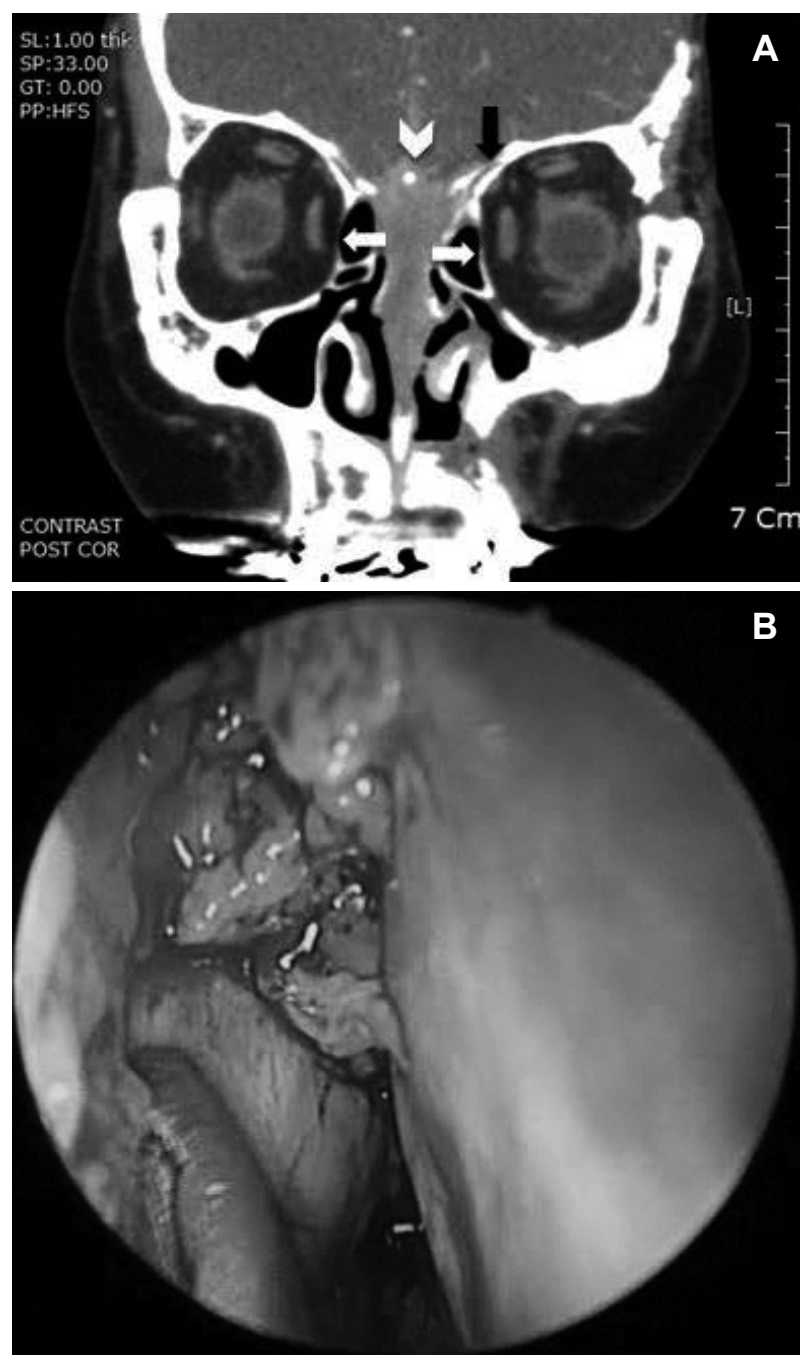

Fig. 2. Coronal computed tomography section of the paranasal area. Note the soft tissue density in the nasal cavity mid line that has destroyed the ethmoid bone, perpendicular plate, and crista galli (white arrowhead). The dense mass extends to both lamellae (white arrows), the left cribriform plate, and the left fovea ethmoidalis (black arrow) (A). Intraoperative findings in the nasal cavity: endoscopy reveals granulation tissue in the nasal cavity and nasal septum $(B)$.

no surgical complications. Histopathologic examination confirmed a proliferative fibroblastic and myofibroblastic lesion with dense lymphoplasmacytic infiltration (Fig. 3). On the basis of these findings, the lesion was diagnosed as an IPT. The patient nasal symptoms improved immediately after surgery, except for the hyposmia, so high-dose oral methylprednisolone was started postoperatively, initially at $80 \mathrm{mg} /$ day, tapered to $60 \mathrm{mg} /$ day after 2 weeks, and to $40 \mathrm{mg} /$ day after a further 4 days. And to $20 \mathrm{mg} /$ day after a further 3 days, and to $10 \mathrm{mg} /$ day after a further 7 days. Low-dose methylprednisolone maintenance therapy ( $5 \mathrm{mg} /$ day) was continued for 7 days. The patient shows no evidence of recurrence after out- 


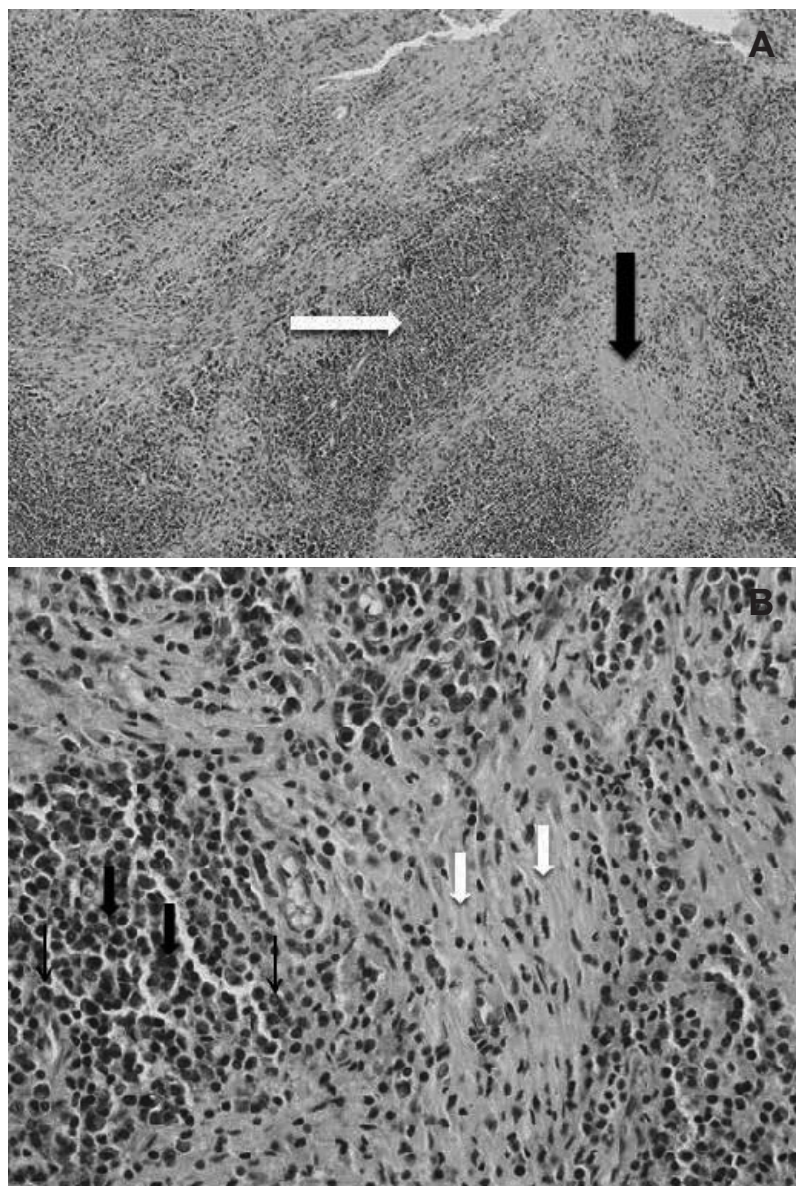

Fig. 3. Biopsy specimen demonstrating a mixed myofibroinflammatory lesion characteristic of inflammatory pseudotumor of the nasal septum. Low-magnification image with stromal (black arrow) and inflammatory (white arrow) elements with deep to well-differentiated squamous epithelium (H\&E stain, $\times 100)(A)$. High magnification image showing spindle cells (thin arrows) and fibrinoid necrosis of myocytes and tissue organization (white arrows) interdigitated with scattered eosinophils, lymphocytes, and plasma cells (thick arrows) (H\&E stain, $\times 200)(B)$.

patient follow-up for about three years (Fig. 4).

\section{Discussion}

Microscopically, an IPT is a space-occupying collection of inflammatory cells, histiocytes, and fibroblasts, but macroscopically has the appearance of a solid tumor. These lesions are most often found in the lungs and orbits. ${ }^{1)}$ Constitutional symptoms are often minimal or absent. The underlying etiology of IPT is unknown, and the majority of cases remain idiopathic as in the case described here. Pseudotumor cerebri is a syndrome of raised intracranial pressure without ventriculomegaly or an intracranial mass, and produces signs and symptoms of raised intracranial pressure such as headache, photophobia, nausea, pulsatile tinnitus, transient visual ob- scurations, visual field defects, papilledema, and the feared visual loss. ${ }^{3)}$ Our patient's chief complaints were diplopia and left ptosis. Differential diagnosis from other malignant and invasive tumors is needed where an enhancing mass is found to involve the left cavernous sinus and dura. IPT should be included in the differential diagnosis where there is a bulging mass with mild contour in the nasal septum, heterogeneous low or intermediate signal intensity on T2-weighted images, an infiltrative appearance with granulation tissue in the nasal septal mucosa, and no known underlying malignancy or adjacent bone destruction.

IPT of the head and neck accounts for less than $5 \%$ of all cases of and most commonly involves the orbit. Although non-orbital pseudotumor has been reported in other areas of the head and neck, IPT of the nasal cavity and nasal septum invading the cavernous sinus is extremely rare. To the authors' best knowledge, pseudotumor cerebri accompanied by oculomotor nerve palsy due to invasion of the cavernous sinus has not been reported previously. Although IPT of the nasal cavity and nasal septum is very rare, it is important for otolaryngologists to be aware of this disease entity.

Radiographically, IPT of the nasal septum tends to be poorly demarcated and has aggressive features, including bone erosion, sclerosis, and remodeling on computed tomography. On magnetic resonance imaging, pseudotumor cerebri lesions are isointense on T1-weighted images and hypointense on T2-weighted images. T1 post-gadolinium enhancement is consistent. The low T2 signal demonstrated here generally favored a differential diagnosis of a granulomatous process, lymphoma, or IPT. Most other pathologic processes are intermediate to high intensity on T2-weighted images.

The pathologic diagnosis of IPT is made by exclusion. Histologic characteristics demonstrate a mixture of spindle cells and inflammatory cells. Fibroblasts, myofibroblasts, plasma cells, lymphocytes, and eosinophils are present in variable proportions. ${ }^{3)}$ Three pathologic subtypes of IPT have been described: a granulation tissue-like pattern (mixed inflammatory); a spindle cell storiform pattern (spindle cell/plasma cell-predominant); and a sparsely cellular, plate-like pattern (eosinophil-predominant). The prognostic implications of these pathologic characteristics are unclear. ${ }^{4)}$

Treatment varies according to the location of the tumor, degree of local invasion, and the likelihood of complete resection being possible. Administration of high-dose corticosteroids is the treatment of choice and usually consists of prednisolone $1 \mathrm{mg} / \mathrm{kg} /$ day for 14 days, followed by a taper. ${ }^{5)}$ 

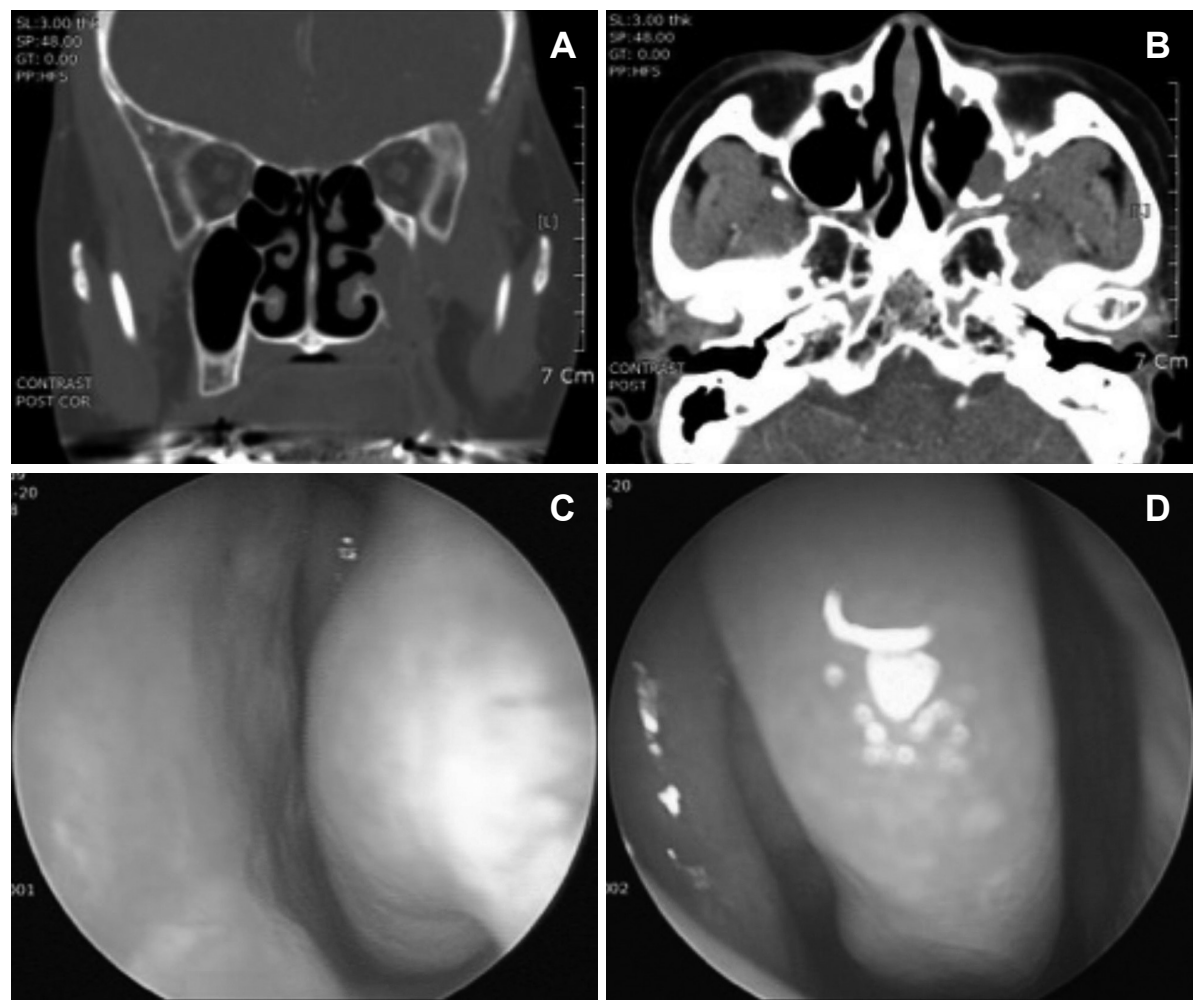

Fig. 4. Findings at three years postoperatively. Follow-up coronal computed tomography images of the paranasal sinus area demonstrate no abnormal findings in the nasal cavity or nasal septum (A). Axial imaging (B). Follow-up endoscopy reveals no significant findings in the nasal cavity or nasal septum (C). Right nasal cavity (D).

Although orbital pseudotumors are fairly responsive to steroid therapy, $17-52 \%$ of patients have some form of recurrence requiring prolonged steroid therapy. This trend may be even greater for non-orbital pseudotumor sites. Our patient was treated with oral prednisolone for four months to prevent a relapse. However, if the response to steroid therapy is poor, complete surgical resection is advocated. ${ }^{6)}$ External beam radiation therapy has been described alone and in combination with surgical resection and/or corticosteroids for this condition. ${ }^{7)}$ Surgical resection and high-dose steroid therapy was the best treatment choice in our case. However, resection of the left cavernous sinus and dura was limited due to the approach used being different from that used for removal of the nasal septal tumor. Due to these limitations, the results of surgical resection need to be followed closely.

Finally, there has been no randomized controlled clinical trial of treatment for IPT reported owing to the low incidence of the disease. Therefore, the treatment strategy is heavily reliant on clinical judgment and practice patterns. This case is important because IPT presented in the brain and nasal septum, including the crista galli, but with a skipped region in between the two lesions. At three years post-treatment, there is no evidence of IPT in this patient.

\section{REFERENCES}

1) Huang WH, Dai YC. Inflammatory pseudotumor of the nasal cavity. Am J Otolaryngol 2006;27(4):275-7.

2) Dehner LP. The enigmatic inflammatory pseudotumours: the current state of our understanding, or misunderstanding. J Pathol 2000;192 (3):277-9.

3) McGeeney BE, Friedman DI. Pseudotumor cerebri pathophysiology. Headache 2014;54(3):445-58

4) Swamy BN, McCluskey P, Nemet A, Crouch R, Martin P, Benger R, et al. Idiopathic orbital inflammatory syndrome: clinical features and treatment outcomes. Br J Ophthalmol 2007;91(12):1667-70.

5) Cho YS, Kim SM, Chung WH, Hong SH. Inflammatory pseudotumour involving the skull base and cervical spine. J Laryngol Otol 2001;115 (7):580-4

6) Ceruse P, Ramade A, Vautrin R, Crozes C, Dubreuil C, Disant F. Inflammatory pseudotumor of the neck: a long-term result without surgical approach. Otolaryngol Head Neck Surg 2005;132(5):812-3.

7) Ruaux C, Noret P, Godey B. Inflammatory pseudotumour of the nasal cavity and sinuses. J Laryngol Otol 2001;115(7):563-6. 